Revista Brasileira de Farmacognosia Brazilian Journal of Pharmacognosy 22(2): 404-411, Mar./Apr. 2012

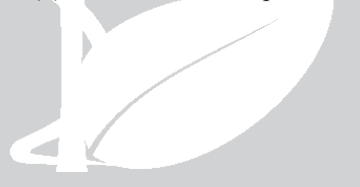

Article

Received 12 Jan 2011

Accepted 25 Jun 2011

Available online 9 Sep 2011

Keywords:

anixiogenic

antianorectic

Ayurvedic formulation

corticotrophin-releasing factor

stress

Trikatu churna

ISSN 0102-695X

http://dx.doi.org/10.1590/S0102-

695X2011005000166

\section{Reversal of CRF- and stress-induced anorexia by an ayurvedic formulation}

\author{
V. S. Kulkarni, " S. J. Surana \\ R. C. Patel Institute of Pharmaceutical Education and Research, India.
}

\begin{abstract}
Trikatu churna is one of the commonly used Ayurvedic formulations in the traditional system of medicine in India for the treatment of agnimandya, i.e. anorexia. Trikatu contains equal amounts of finely powdered rhizomes of Zingiber officinale Roscoe (Zingiberaceae) and fruits of Piper longum L. and Piper nigrum L. (Piperaceae). The chief objective of the study was to determine the antianorectic effects of three drugs individually and to compare these effects with the effect of Trikatu. The activity of the drugs was studied after anorexia was induced in rats by (1) physical stress arising from immobilization for 60 min; (2) intraperitoneal injection of Escherichia coli lipopolysaccharide (LPS, $100 \mu \mathrm{g} / \mathrm{kg}$ body weight); and (3) intraperitoneal administration of fluoxetine $(8 \mathrm{mg} / \mathrm{kg}$ body weight). Similar doses of the extracts were tested on freely feeding rats and on rats that had been deprived of food for $20 \mathrm{~h}$. Corticotrophinreleasing factor (CRF, $0.3 \mu \mathrm{g} / \mathrm{rat}$ ) can induce anxiogenic-like behavior and reduced food intake. This model was also studied, and the results were compared. The components of Trikatu churna failed to individually reverse the inhibition of feeding. In contrast, Trikatu churna pretreatment reversed stress-, fluoxetine- and CRF-induced anorexia. The study provides strong evidence of the synergistic action of Ayurvedic formulas and also proves the ability of Trikatu churna to reduce stress and CRF-induced anorexia.
\end{abstract}

\section{Introduction}

The term anorexia describes any loss of appetite and the concomitant reduction in food intake that occurs in the presence of readily accessible food sources. Anorexia is a major contributor to cachexia, a condition of advanced protein calorie malnutrition that leads to invasive, expensive nutrition support therapy, iatrogenic infections and mortality and has a poor response to therapy.

Patients with life-altering diseases generally experience psychological stress at the uncertainties involved with the diagnosis, treatment and final outcome of the diseases. This psychological stress can affect the food intake of the patients. Anorexia may develop temporarily as a part of the adaptive response to stress (Watts \& Salter, 2004). Restraint and immobilization are the stressors used most frequently to investigate this type of anorexia (Marti et al., 1994). A temporary stress might affect the mechanisms in the body that regulate energy expenditure and food intake (Smith, 1989). Stress is responsible for the release of corticotrophin-releasing factor $(\mathrm{CRF})$ in the hypothalamic region, which in turn inhibits feeding. If CRF is administered centrally, it can induce anxiogenic-like behavior and reduced food intake (Morley \& Levine, 1982). If administered by the intravenous route (i.v.) or intraperitoneally (i.p.), it is found to inhibit gastric emptying (Tache et al., 1987).

Furthermore, complex neuronal mechanisms are also involved in the inhibition of feeding. Proinflammatory cytokines play an important role in the inhibition of feeding by stimulation of tumor necrosis factor- $\alpha$ (TNF- $\alpha$ ) and interleukin-1 (IL-1). This release of cytokines can be stimulated by ingestion of the lipopolysaccharide (LPS) of bacterial cell walls (O'Reilly et al., 1988). The available data suggest that the serotonergic system also plays a role in the mediation of cytokine-induced inhibition of feeding. Fluoxetine, which is a selective 5-hydroxy tryptamine (5-HT) reuptake inhibitor, can induce anorexia (Mattioli \& Perfume, 2007). Various models have been developed for investigating anorexia in relation to synthetic drugs. However, the claims regarding the antianorectic role of traditional drugs remain unexplored.

The present study deals with the antianorectic effect of a drug that is commonly prescribed by Indian Ayurvedic practitioners, Trikatu churna, for the treatment of agnimandya (anorexia). Trikatu churna contains equal amounts of finely powdered rhizomes of Zingiber officinale Roscoe (Zingiberaceae) and fruits of Piper longum L. and Piper nigrum L. (Piperaceae) (Anonymous, 
1976). Of the 370 formulations listed in the Handbook of Domestic Medicine and Common Ayurvedic Remedies, 210 contain either Trikatu or its components (Annamalai $\&$ Manavalan, 1990). The aim of the study was to verify the antianorectic effects of the components of the Trikatu formulation (TF) and to compare them with the effects of Trikatu. Herbal formulations are favored in Ayurveda. This is because the founders of Ayurveda recognized the possible synergistic and counterbalancing effects of herbs (Mishra, 2004). Sometimes none of the herbs in a formulation exhibits therapeutic effects individually; but the formulation may be effective (Bhattacharya et al., 1997). A survey of the literature revealed an absence of reports on the antianorectic activity of Trikatu churna. So the study was designed to support the claim.

The constituents of TF, i.e. powders of Zingiber officinale (ZO), Piper longum (PL) and Piper nigrum (PN), were selected for the study. The published material available regarding the acute toxicity of $\mathrm{ZO}, \mathrm{PL}, \mathrm{PN}$ and $\mathrm{TF}$ indicates that TF and its constituents are safe up to a level of $2000 \mathrm{mg} / \mathrm{kg}$ (Shalaby \& Hamowieh, 2010; Shah et al., 1998; Patil et al., 2008; Chanda et al., 2009). Doses of 100,200 and $400 \mathrm{mg} / \mathrm{kg}$ were selected for the study, in accordance with OECD Guideline 423 (1987). The dose at which $\mathrm{ZO}, \mathrm{PL}$ and $\mathrm{PN}$ displayed activity was to be taken for comparison with TF. In the case of an absence of any response, the highest dose, i.e. $400 \mathrm{mg} / \mathrm{kg}$, was to be selected for comparison with TF.

\section{Materials and Methods}

\section{Animals}

Male Wistar rats weighing 250-300 g were used in the antianorectic tests. All animals were individually housed in a cage, maintained at $22 \pm 2{ }^{\circ} \mathrm{C}$ in a room with a 12-h light/dark cycle (lights on at $6 \mathrm{am}$ ) and had free access to feed and water ad libitum during a quarantine period. The study complied with the current ethical regulations on animal research and related rules of our institute, and all animals used in the experiment received humane care. All the pharmacological experimental protocols were approved by the institutional animal ethics committee (Resolution No. RCPIPER/IAEC/2009-10/11).

\section{Preparation of formulation}

The formulation was prepared as prescribed by the Ayurvedic Formulary of India, part I. Rhizomes of Zingiber officinale Roscoe, Zingiberaceae, and fruits of Piper longum L. and Piper nigrum L., Piperaceae, were taken in equal parts, powdered and mixed uniformly. All the raw materials were purchased from the local market. The plant materials were authenticated, and voucher specimens were deposited at Agharkar
Research Institute, Pune, Maharashtra, India, with following voucher specimen numbers: $Z$. officinale, R-106; P. longum, F-145; and P. nigrum, F-144.

\section{Drugs}

HPLC analysis of dry hydroalcoholic extracts of Zingiber officinale, Piper longum and Piper nigrum revealed the presence of $1.05 \mathrm{mg} / \mathrm{g}$ of 6 -gingerol, 3.09 $\mathrm{mg} / \mathrm{g}$ of piperine and $3.14 \mathrm{mg} / \mathrm{g}$ of piperine in them, respectively. A dry hydroalcoholic extract of the prepared TF was also analyzed by HPLC. The analysis report showed the presence of $4.4 \mathrm{mg} / \mathrm{g}$ of piperine and 0.7 $\mathrm{mg} / \mathrm{g}$ of 6-gingerol in the formulation. All the extracts were dissolved in absolute ethanol and diluted with tap water in order to obtain a final ethanol concentration of $1 \% \mathrm{v} / \mathrm{v}$ in all treatments. Each extract was administered intragastrically at doses of 100, 200 and $400 \mathrm{mg} / \mathrm{kg}$ body weight, and a control group was administered a similar vehicle.

CRF(rat; Sigma-Aldrich Germany) was dissolved in sterile isotonic saline prior to use and administered by the intravenous route (i.v.) at a dose of $0.3 \mu \mathrm{g} / \mathrm{rat}$. Lipopolysaccharide (LPS) from E. coli (Sigma-Aldrich Germany) was dissolved in pyrogen-free isotonic saline and administered by intraperitoneal injection (i.p.) at a dose of $100 \mu \mathrm{g} / \mathrm{kg}$ body weight. Fluoxetine hydrochloride (FLU; Sigma-Aldrich Germany) was dissolved in sterile physiological saline and administered i.p. at a dose of 8 $\mathrm{mg} / \mathrm{kg}$.

\section{Experimental procedure}

All experiments were carried out at $10.30 \mathrm{am}$, during the light phase of the light/dark cycle.

Effects of TF and its constituents on food intake in freely feeding rats

To evaluate the general effect of $\mathrm{ZO}, \mathrm{PL}, \mathrm{PN}$ and TF on food intake, the effects of all extracts were examined in freely feeding rats. The animals were divided into thirteen groups with eight animals each. All animals received an intragastric administration of the vehicle, $\mathrm{ZO}$, PL, PN and TF in doses of 100, 200 and $400 \mathrm{mg} / \mathrm{kg}$. Their food was removed for $1 \mathrm{~h}$ and offered again later. The food consumption was recorded at 30, 60, 90 and 120 min and at 4, 6 and $24 \mathrm{~h}$ after administration of the test extract administration, by weighing the food cups and by subtracting the spillage from the total food intake.

Effects of TF and its constituents on restraint stressinduced anorexia

All rats $(n=117)$ were subjected to food 
deprivation for $20 \mathrm{~h}$ to evaluate the effects of all extracts on food consumption under restraint stress conditions and then given an intragastric administration of the vehicle, ZO, PL, PN and TF (100, 200 and $400 \mathrm{mg} /$ $\mathrm{kg}$ ). One hour later, restraint stress was induced in the rats by restraining them in cylindrical Plexiglas tubes for $60 \mathrm{~min}$ (Ciccocioppo et al., 2001). After a restraint period of $60 \mathrm{~min}$, the rats were returned to their home cages and offered food ad libitum. The food consumption was recorded 30, 60, 90 and $120 \mathrm{~min}$ and 4, 6 and 24 $\mathrm{h}$ later. Control group animals $(\mathrm{n}=10)$ were deprived of food but not subjected to restraint stress. They received an intragastric administration of the vehicle and were returned to their home cages.

Effects of TF and its constituents on LPS-induced anorexia

LPS is a pathogenic agent that induces a moderate infection that is associated with a reduction in food consumption (Langhans et al., 1989). The rats $(\mathrm{n}=100)$ were deprived of food for $20 \mathrm{~h}$ and then injected with $100 \mu \mathrm{g} / \mathrm{kg}$ LPS. Four hours later, they received an intragastric administration of the vehicle, $\mathrm{ZO}, \mathrm{PL}, \mathrm{PN}$ and TF $(100,200$ and $400 \mathrm{mg} / \mathrm{kg})$. Control group rats $(n=10)$ were deprived of food and received the vehicle. Sixty min after administration of the test extracts, the rats were provided food, and the food consumption of each rat was determined 30, 60, 90 and $120 \mathrm{~min}$ and 4, 6 and $24 \mathrm{~h}$ later.

\section{Effects of TF on fluoxetine-induced anorexia}

Fluoxetine is a selective 5-HT reuptake inhibitor that causes a reduction in food intake. It can be beneficial to evaluate the selectivity of the antianorectic effect of TF. Rats $(n=104)$ were deprived of food for $20 \mathrm{~h}$. They received an intragastric administration of the vehicle, ZO, PL, PN and TF (100, 200 and $400 \mathrm{mg} / \mathrm{kg})$, and 60 min later, they were injected (i.p.) with FLU $(8 \mathrm{mg} / \mathrm{kg})$ (Currie et al., 2004). Thirty min later, all rats were given free access to food, and their food consumption was recorded 30, 60, 90 and $120 \mathrm{~min}$ and 4, 6 and $24 \mathrm{~h}$ later. Control group animals were deprived of food and were given an i.g. administration of the TF vehicle, after which they were given a FLU vehicle injection (i.p.) to observe the effect of FLU on the food consumption.

\section{Effects of TF on food intake of food-deprived rats}

To correlate the hypophagic effect of stress with the orexigenic action of TF and its components, the effects of the extracts on the food consumption of food-deprived rats that were not subjected to stress conditions were evaluated. In this experiment, food-deprived rats $(n=104)$ received an i.g. administration of the vehicle, $\mathrm{ZO}, \mathrm{PL}$, $\mathrm{PN}$ and TF (100, 200 and $400 \mathrm{mg} / \mathrm{kg}$ ); the control group $(n=10)$ consisted of nondeprived rats. Food was offered ad libitum $1 \mathrm{~h}$ after administration, and the food intake was recorded 30, 60, 90 and $120 \mathrm{~min}$ and 4, 6 and $24 \mathrm{~h}$ later.

\section{Effects of TF on CRF-induced anorexia}

CRF (0.15-10 $\mu \mathrm{g}, i . v$.) inhibited gastric emptying in rats in a manner similar to the reduction in food intake caused by partial restraint stress (Dunn \& Berridge, 1990). To evaluate this effect, rats $(n=104)$ deprived of food for $20 \mathrm{~h}$ received an intragastric administration of the vehicle, ZO, PL, PN and TF (100, 200 and $400 \mathrm{mg}$ / $\mathrm{kg}$ ), and $60 \mathrm{~min}$ later they were given an i.v. injection of CRF $(0.3 \mu \mathrm{g} / \mathrm{rat} / \mathrm{mL})$. Rats were given free access to food 20 min after the CRF injection, and their food intake was determined 30, 60, 90 and $120 \mathrm{~min}$ and 4, 6 and 24 $\mathrm{h}$ later. The control group received $(\mathrm{n}=8)$ i.g. and i.v. administrations of the TF and CRF vehicles respectively, to observe the effects of CRF.

\section{Statistical analysis}

The data obtained in the foregoing experiments were analyzed by two-way ANOVA, followed by a post hoc Bonferroni test. Values are presented in the figures as the mean \pm SEM for each group of animals, with the number of animals in the group indicated (n). $p$ values less than 0.05 were considered significant.

\section{Results}

Effects of TF and its constituents on food intake in freely feeding rats

The extract of TF and its constituents (ZO, PL, PN) did not modify the food intake of freely feeding rats at any of the doses tested. As shown in Figure 1, the statistical analysis revealed no significant effect on the food consumption of freely feeding rats up to $4 \mathrm{~h}$. While TF $(400 \mathrm{mg} / \mathrm{kg})$ showed a significant effect at 6 and $24 \mathrm{~h}(p<0.05 ; \mathrm{F}=31.39)$. As this is a behavioral study, the significance cannot be totally attributed to the drug treatment. The increased food intake at the end of the study of only one group can be ignored.

Effects of TF and its constituents on restraint stressinduced anorexia

Imposition of the restraint stress significantly reduced the food intake in rats compared with nonstressed rats (Figure 2). Pretreatment with TF (400 mg/kg) significantly reversed the anorectic effect of the restraint 
stress (Figure 3 ). The effect started 120 min after drug administration $(p<0.05)$ and lasted up to $24 \mathrm{~h}(p<0.0001$; $\mathrm{F}=19.95$ ). The constituents, viz. ZO, PL and PN, did not show statistically significant results $(p>0.05)$ individually at doses of 100 and $200 \mathrm{mg} / \mathrm{kg}$; at $24 \mathrm{~h}, \mathrm{PL}$ and PN showed significant effects at $400 \mathrm{mg} / \mathrm{kg}(p<0.05)$. The effect of TF (100 and $200 \mathrm{mg} / \mathrm{kg}$ ) was also not statistically significant $(p>0.05)$.

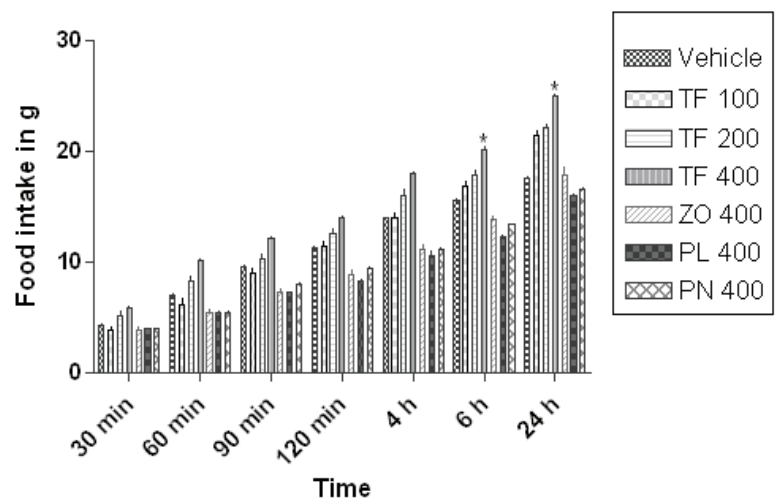

Figure 1. Comparative effect of TF and its constituents (ZO, PL and $\mathrm{PN}$ ) on freely feeding rats. Effects of i.g. administration of vehicle and TF $(100,200$ and $400 \mathrm{mg} / \mathrm{kg})$ and ZO, PL and PN $(400 \mathrm{mg} / \mathrm{kg}$ ) on cumulative food intake in freely feeding rats. Data represent mean food intake $\left( \pm\right.$ SEM) of ten rats. ${ }^{*} p<0.05$, significant differences from the vehicle-treated rats; where not indicated, the differences are not statistically significant.

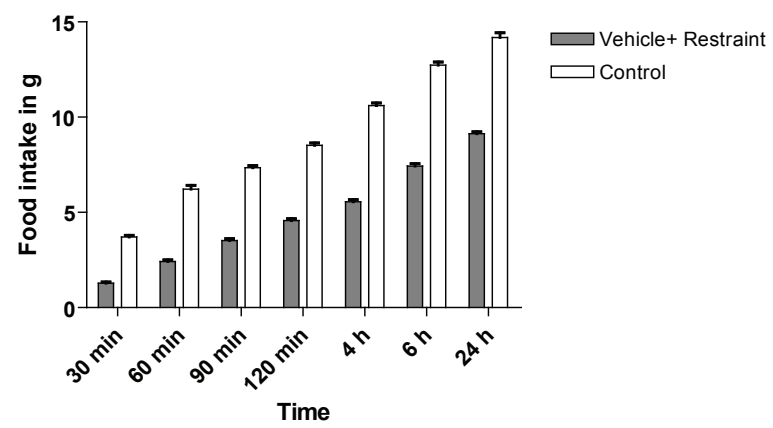

Figure 2. Effect of restraint stress on food intake of rats. Cumulative food intake in rats deprived of food for $20 \mathrm{~h}$ and subjected to restraint stress (vehicle+restraint), compared with a food-deprived group that was administered the TF vehicle $i . g$. but not subjected to stress.

\section{Effects of TF and its constituents on LPS-induced anorexia}

As shown in Figure 4, i.p. administration of LPS induced a marked reduction in the food intake of the rats. Pretreatment with TF and its constituents did not modify the feeding behavior significantly at any of the doses tested $(p<0.05 ; \mathrm{F}=14.80)$ (Figure 5).

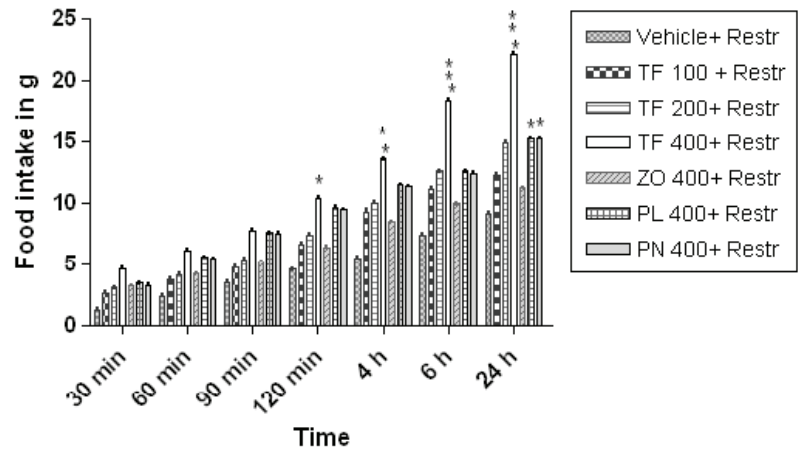

Figure 3. Comparison of effects of TF and its constituents on stress-induced anorexia. Effects of $i . g$. administration of vehicle (vehicle+restraint) and TF $(100,200$ and $400 \mathrm{mg} / \mathrm{kg})$ and ZO, $\mathrm{PL}$ and PN (400 mg/kg) on restraint stress-induced anorexia. Data represent mean food intake $\left( \pm\right.$ SEM) of 10 rats. ${ }^{*} p<0.05$, $* * p<0.01, \quad * * * p<0.001$, significant differences from the vehicle-treated rats; where not indicated, the differences are not statistically significant.

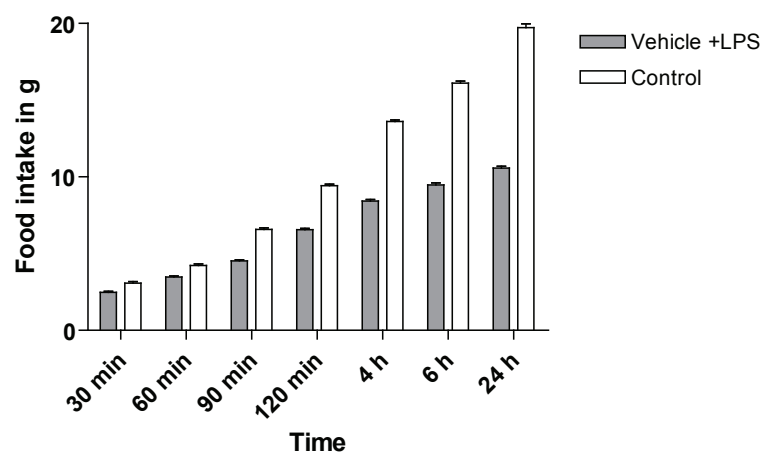

Figure 4. Effect of LPS on food intake of rats. Cumulative food intake in rats deprived of food for $20 \mathrm{~h}$ and administered LPS (by i.p. injection) (vehicle+LPS), compared with a fooddeprived control group that was i.g. and i.p. administered TF and LPS vehicle, respectively.

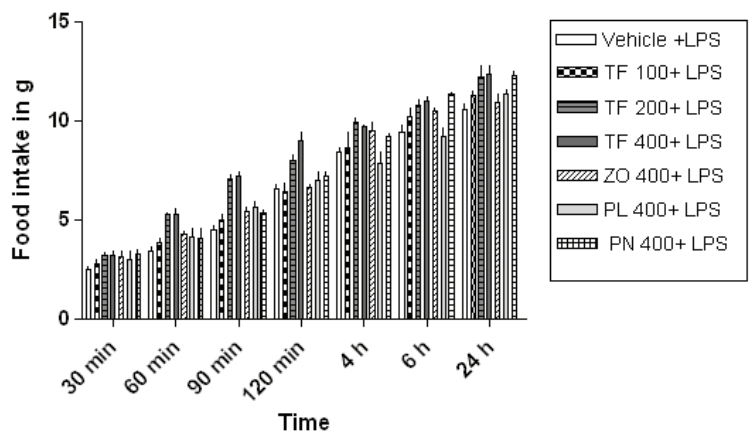

Figure 5. Comparison of effects of TF and its constituents, $\mathrm{ZO}, \mathrm{PL}$ and PN, on LPS-induced anorexia. Effects of i.g. administration of vehicle (vehicle+LPS) and TF (100, 200 and $400 \mathrm{mg} / \mathrm{kg}$ ) and ZO, PL and PN (400 mg/kg) on LPSinduced anorexia. Data represent mean food intake $( \pm \mathrm{SEM})$ 
of 10 rats. ${ }^{*} p<0.05, \quad * * p<0.01, \quad * * * p<0.001$, significant differences from the vehicle-treated rats; where not indicated, the differences are not statistically significant.

Effects of TF and its constituents on fluoxetine-induced anorexia

As shown in Figure 6, i.p. administration of fluoxetine produced a marked inhibition in feeding. Pretreatment with TF $(200 \mathrm{mg} / \mathrm{kg})$ resulted in a significant effect after $90 \mathrm{~min}(p<0.05)$ and at the end of study significance was increased $(p<0.01 ; \mathrm{F}=34.32)$. Similarly TF (100 and $400 \mathrm{mg} / \mathrm{kg}$ ), PL and PN (400 mg/kg) showed the statistically increased food intake at the end of the study. However, as previously discussed, behavioral patterns may interfere with the study, and so the results obtained cannot be considered to be arising from the effects of the drug treatment alone Figure 7.

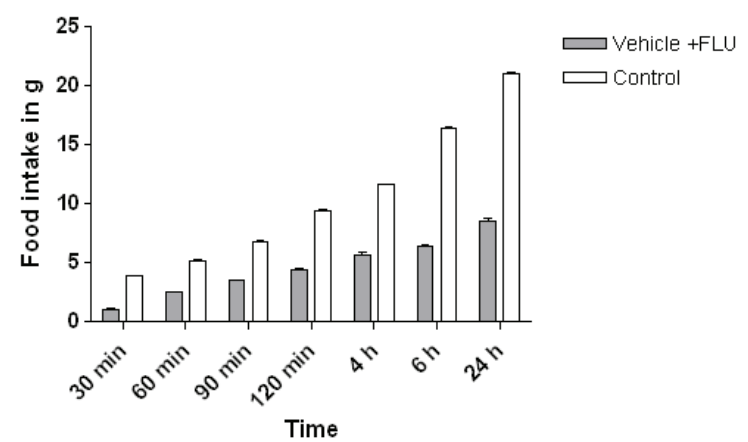

Figure 6. Effect of fluoxetine on food intake of rats. Cumulative food intake in rats deprived of food for $20 \mathrm{~h}$ and administered FLU (by i.p. injection) (vehicle+FLU), compared with a fooddeprived control group that was i.g. and i.p. administered TF and FLU vehicle, respectively.

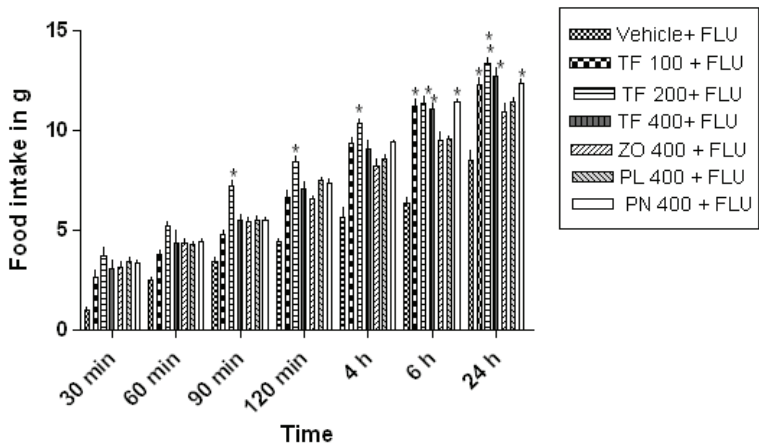

Figure 7. Effect of TF and its constituents on fluoxetineinduced anorexia. Effects of i.g. administration of vehicle (vehicle+FLU) and TF (100, 200 and $400 \mathrm{mg} / \mathrm{kg}$ ) and ZO, PL and PN (400 mg/kg) on FLU-induced anorexia. Data represent mean food intake $( \pm \mathrm{SEM})$ of 10 rats. ${ }^{*} p<0.05, * * p<0.01$, $* * * p<0.001$, significant differences from the vehicle-treated rats; where not indicated, the differences are not statistically significant.
Effects of TF and its constituents on food intake of fooddeprived rats

Deprivation of food did not increase the food intake significantly compared with nondeprived rats. Pretreatment with TF $(100,200$ and $400 \mathrm{mg} / \mathrm{kg})$ and its constituents, ZO, PL and PN (400 mg/kg), had no significant effect on the feeding of the rats $(p>0.05$; $\mathrm{F}=2.32$ ) (Figure 8).

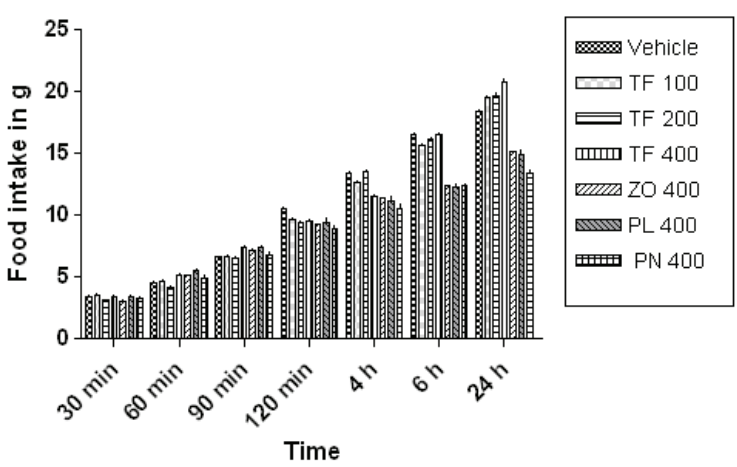

Figure 8. Effect of TF and its constituents on food intake of food-deprived rats. Effects of $i . g$. administration of vehicle and TF $(100,200$ and $400 \mathrm{mg} / \mathrm{kg})$ and ZO, PL and PN on cumulative food intake in rats deprived of food for $20 \mathrm{~h}$. Data represent mean food intake ( \pm SEM) of ten rats. The differences between rats treated with TF and its constituents and the vehicle-treated group are not statistically significant.

Effects of TF and its constituents on CRF-induced
anorexia

Intravenous injections of CRF induced a marked inhibition in the feeding of rats (Figure 9). Statistical analysis revealed that pretreatment with TF at a dose of $400 \mathrm{mg} / \mathrm{kg}$ had a significant antianorectic action $(p<0.05)$ from $60 \mathrm{~min}$ onward and the significance increased at $24 \mathrm{~h}(p<0.001 ; \mathrm{F}=33.08)$. At a dose of 200 $\mathrm{mg} / \mathrm{kg}$, TF showed highly significant activity $(p<0.05)$ from $90 \mathrm{~min}$, and the significance increased up to $24 \mathrm{~h}(p<0.01)$. But at $100 \mathrm{mg} / \mathrm{kg}$ it could not reverse the anorectic effect of CRF up to $4 \mathrm{~h}$. After $4 \mathrm{~h}$ of treatment, TF $(100 \mathrm{mg} / \mathrm{kg}), \mathrm{PL}$ and $\mathrm{PN}(400 \mathrm{mg} / \mathrm{kg})$ had statistically significant effects on the food intake $(p<0.05)$. While the effect of ZO $(400 \mathrm{mg} / \mathrm{kg})$ started from $4 \mathrm{~h}(p<0.05)$, it was highly significant from 6 to $24 \mathrm{~h}(p<0.01)$ (Figure 10).

\section{Discussion}

The present study ascertains that TF extract effectively and in a dose-dependent manner reduces the marked anorexia induced by stress. Pretreatment with $\mathrm{TF}$ extract at doses of 200 and $400 \mathrm{mg} / \mathrm{kg}$ significantly 
reversed the anorectic effect induced by restraint stress and by administration of FLU and CRF. The antianorectic effect appeared within 60-90 min after a single-dose administration of TF extract, and this effect lasted up to $24 \mathrm{~h}$.

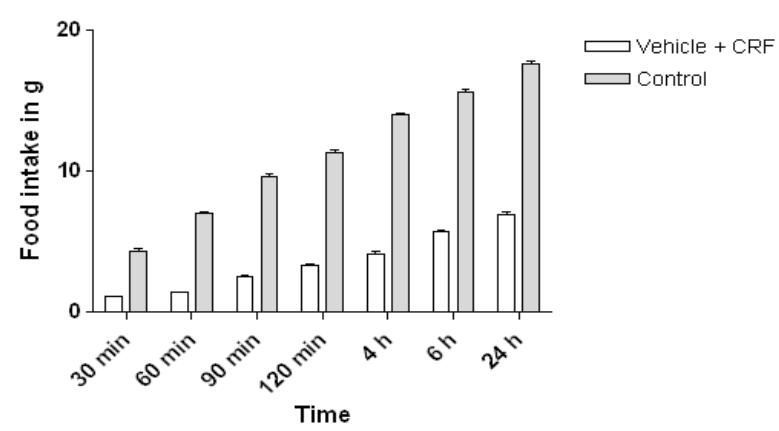

Figure 9. Effect of CRF on food intake of rats. Cumulative food intake in rats deprived of food for $20 \mathrm{~h}$ and administered CRF (by i.v. injection) (vehicle+CRF) compared with a fooddeprived control group that was i.g. and i.v. administered TF and CRF vehicle, respectively.

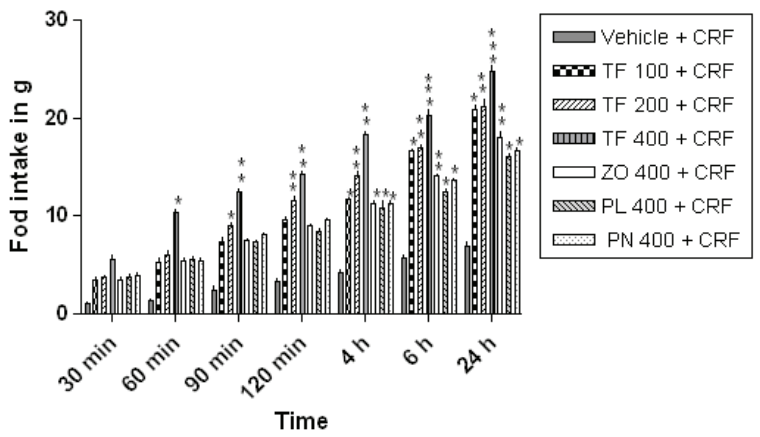

Figure 10. Comparison of effects of TF and its constituents on CRF-induced anorexia. Effects of i.g. administration of vehicle (vehicle+CRF) and TF $(100,200$ and $400 \mathrm{mg} / \mathrm{kg}$ ) and ZO, PL and PN $(400 \mathrm{mg} / \mathrm{kg})$ on CRF-induced anorexia. Data represent mean food intake $( \pm \mathrm{SEM})$ of 10 rats. ${ }^{*} p<0.05$, $* * p<0.01, \quad * * * p<0.001$, significant differences from the vehicle-treated rats; where not indicated, differences are not statistically significant.

On the other hand, the individual constituents, $\mathrm{ZO}, \mathrm{PL}$ and PN, did not show any significant effect on the restraint stress condition, whereas they had a significant action on CRF-induced anorexia at a higher dose, $400 \mathrm{mg} / \mathrm{kg}$. TF, a combined formulation of $\mathrm{ZO}$, $\mathrm{PL}$ and $\mathrm{PN}$, showed significant antianorectic action toward restraint stress at a dose of $400 \mathrm{mg} / \mathrm{kg}$ and also showed significant action to CRF-induced anorexia at a dose of $200 \mathrm{mg} / \mathrm{kg}$ and a highly significant action at 400 $\mathrm{mg} / \mathrm{kg}$. Thus, the present study supports the concept of synergism in Ayurveda. The antianorectic effect of TF can be attributed to the synergistic action of ZO, PL and
PN. Piper longum and Piper nigrum are rich sources of piperine, which is a strong bioavailability enhancer (Atal et al., 1981). Piperine might be responsible for enhancing the bioavailability of the other compounds in the formulation such as gingerols and shogaols, which are responsible for the antianorectic action or might be acting as antianorectic agents. Work on the ability of individual markers to reverse the anorectic effect is necessary.

The present study shows that at the different doses used, TF or its constituents do not increase food intake in freely feeding rats or in nonstressed, fooddeprived rats (normophagic animals). Restriction of the diet or deprivation of food is responsible for stimulating synthesis of neuropeptide $\mathrm{Y}$, which is a powerful orexigenic agent (Dong-Yih et al., 2001). We did not find any significant difference in the food intakes of TF-treated and vehicle-treated, food-deprived rats. This suggests that the inhibitory effect of TF on restraint stress-induced and CRF-induced anorexia is not related to a nonspecific orexigenic action.

TF also failed to reverse the anorectic effect of LPS at any of the doses tested. LPS are purified Gram-negative bacterial cell wall constituents that are released after bacteriolysis or during periods of rapid bacterial proliferation (Rietschel et al., 1998). As in a systemic action of microbial infections, LPS stimulates a proinflammatory cytokine response and many host reactions including anorexia. i.p. administered LPS (doses $\leq 150 \mu \mathrm{g} / \mathrm{kg}$ ) inhibits food intake, which is independent of a concomitant water intake or gastric emptying (Langhans, 1996). LPS induces anorexia by triggering the synthesis of different proinflammatory cytokines such as interleukin-1 (IL-1), interleukin-6 (IL-6), tumor necrosis factor- $\alpha$ (TNF- $\alpha$ ) and interferon- $\alpha$ (INF- $\alpha$ ). It has been suggested that both TNF- $\alpha$ and IL-1 act as mediators in the anorexic response (Watts \& Salter, 2004). TNF- $\alpha$ and IL-1 stimulate leptin release, which affects the food intake both in experimental animals and in humans (Grunfeld et al., 1996). IL-1 in particular is a potent modulator of hypothalamic areas and increases hypothalamic corticotrophin-releasing factor (CRF), which in turns induces anorexia.

Administration of CRF (i.v.) induces anorexia by inhibiting gastric emptying. TF extract can reverse the effect of CRF but is unable to reverse the anorexia induced by i.p. administered LPS since LPS-induced anorexia involves various cytokines and multiple chemical and neuronal mechanisms besides having a direct effect on gastrointestinal activity.

Similarly, serotonin system also plays an important role in the control of feeding inhibition. Serotonin potently inhibits eating particularly through the $5-\mathrm{HT}_{1 \mathrm{~b}}$ or $5-\mathrm{HT}_{2 \mathrm{c}}$ receptors (Simansky, 1996) i.p. administration of fluoxetine, a selective 5-HT reuptake 
inhibitor, produces inhibition of eating by increasing the extracellular levels of 5-HT in the forebrain region (Romero \& Artigas, 1997). TF extract reverses this effect. Overall, the data suggest that the action of TF extract is specific to stress- and CRF-induced anorexia and interferes with the serotonergic pathway. CRF (i.v.) inhibited gastric emptying in rats, and this effect of CRF was prevented by $i . v$. antiserum to CRF but not altered by bretylium (a noradrenergic blocker) or chorisondamine (a ganglionic blocking agent) (Lenz et al., 1988). The overall results of the study suggest that TF may show an antianorectic effect by acting as a CRF antagonist. Further studies are necessary to prove this hypothesis.

Stress-induced anorexia has been proposed as a useful model of certain human anorectic conditions, particularly those precipitated by life event stresses or those associated with affective disorders that are often resistant to conventional antianorectic agents. Therefore, regardless of the mechanisms involved, the antianorectic effect of acute-dose TF (200 and $400 \mathrm{mg} / \mathrm{kg}$ ) is of potential clinical interest as the effect is shown within 60-90 min and lasts up to $24 \mathrm{~h}$.

In conclusion, the present study highlighted the synergistic effect of an Ayurvedic formulation and is a preliminary step toward the pharmacological exploration of the claims of Ayurvedic drugs.

\section{References}

Annamalai AR, Manavalan R 1990. Effect of Trikatu and its individual component and Piperine on gastrointestinal tract: Trikatu - A bioavailability enhancer. Indian Drugs 27: 595-604.

Anonymous 1976. The Ayurvedic formulary of India part-I. $\mathrm{I}^{\mathrm{st}}$ ed. Delhi: Government of India Ministry of Health and Family welfare, p. 89

Atal CK, Zutshi U, Rao PG 1981. Scientific evidence on the role of Ayurvedic herbals on bioavailability of drugs. $J$ Ethnopharmacol 4: 229-232.

Bhattacharya SK, Satyan K, Chakrabaarti A 1997. Effect of Trasina, an Ayurvedic herbal formulation, on pancreatic islet superoxide dismutase activity in hyperglycemic rats. Indian J Exp Biol 35: 297-299.

Chanda D, Shankar K, Pal A, Lugman S, Bawankule DU, Mani D, Darokar MP 2009. Safety evaluation of Trikatu, a generic ayurvedic medicine in Charles Foster rats. $J$ Toxicol Sci 34: 99-108.

Ciccocioppo R, Martin Fardon R,Weiss F, Massi M 2001. Nocicetin/orphanin FQ inhibits stress and CRF induced anorexia in rats. Neurol Rep 12: 1145-1149.

Currie PJ, Braver M, Mirza A, Sricharoon K 2004. Sex differences in the reversal of fluoxetine induced anorexia following raphe injections of 8-OH-DPAT. Psychophrmacology 172: 359-364.

Dong-Yih K, Chao TH, Juei-Tang C 2001. Role of hypothalamic
Neuropeptide Y (NPY) in the change of feeding behavior induced by repeated treatment of Amphetamine. Life Sci J 70: 243-351.

Dunn AJ, Berridge CW 1990. Physiological and behavioral responses to corticotropin-releasing factor administration: is CRF a mediator of anxiety or stress responses. Brain Res Rev 15: 71-100.

Grunfeld C, Pang M, Shigenaga J, Jensen P, Lallone R, Friedman J, Feingold KR 1996. Serum leptin levels in the acquired immunodeficiency syndrome. J Clin Endocrinol metab 81: 4342-4346.

Langhans W, Harlachekar R, Scharrer E 1989. Verapamil and Indomethacin attenuate endotoxin induced anorexia. Physiol Behav 46: 535-539.

Langhans W 1996. Bacterial products and the control of ingestive behavior: clinical implications. Nutrition 12: 303-315.

Lenz HJ, Raeder A, Greten H, Vale WW, Rivier JE 1988. Stress induced gastrointestinal secretory and motor responses in rats are mediated by endogenous corticotropin releasing factor. Gastroenterology 95: 1510-1517.

Marti O, Marti J, Armario A 1994. Effects of chronic stress on food intake in rats: influence of stressor intensity and duration of daily exposure. Physiol behav 55: 747-753.

Mattioli L, Perfume M 2007. Rhodiola rosea L.extract reduces stress and CRF induced anorexia in rats. $J$ Psychopharmacol 21: 742-750.

Mishra LC 2004. Scientific basis for Ayurvedic therapies. CRC press 2: 27.

Morley JE, Levine AS 1982. Corticotrophin releasing factor, grooming and ingestive behavior. Life Sci 31: 14591464.

O’Reilly B, Vander AJ, Kluger MJ 1988. Effects of chronic infusion of lipopolysaccharide on food intake and body temperature of rat. Physiol Behav 42: 287-291.

Rietschel ET, Schletter J, Weidemann B, El-Samalouti V, Mattern T, Zahringer U, Seydel U, Brade H, Flad HD, Kusumoto S, Gupta D, Dziarski R, Ulmer AJ 1998. Lipopolysaccharide and peptidoglycan: CD14dependant bacterial inducers of inflammation. Microbe Drug Resistance 4: 37-44.

Romero L, Artigas F 1997. Preferential potentiation of the effects of serotonin uptake inhibitors by 5-HT1A receptor antagonist in the dorsal raphe pathway- role of somatodendritic autore captors. J Neurochem 63: 25932603.

Shah AH, Al-Shareef AH, Ageeel AM, Qureshi S 1998. Toxicity studies in mice of common spices, Cinnamomum zeylenicum bark and Piper lingum fruits. Plant Food Hum Nutr 52: 231-239.

Shalaby MA, Hamowieh AR 2010. Safety and efficacy of Zingiber officinale on fertility of male diabetic rats. Food Chem Toxicol 48: 2920-2924.

Patil S, Suvarna V, Fulmali S 2008. Anti-inflammatory activity of Piper nigrum, Linn and Ricinus communis, 
Linn. http://www.biology-online.org/articles/antiinflammatory-activity-piper-nigrum-linn.html, access in April 2010.

Simansky KJ 1996. Serotonergic control of the organization of feeding and satiety. Behav Brain Re 73: 37-42.

Smith GP 1989. Animal models of human eating disorders. Ann NY Acad Sci 575: 63-72.

Tache Y, Maeda-Hagiwara M, Turkelson CM 1987. Central nervous system action of corticotrophin releasing factor to inhibit gastric emptying in rats. Am J Physiol: G241G245.

Watts AG, Salter D 2004. Neurobiology of food and fluid intake. In Handbook of behavioral neurobiology. 2 ed. Vol 14., New York: Plenum Publishers, p. 383 417.

\section{*Correspondence}

Vishakha S. Kulkarni

R. C. Patel Institute of Pharmaceutical Education and Research Karwand Naka, Shirpur, Dist. Dhule, Maharashtra, India, 425405

kulkarnivishakha@rediffmail.com

Tel.: +912563255189

Fax: +912563251808 